\title{
Real-Time Deepwater Current Profiling System
}

\author{
Michael Vogel, Shell Global Solutions (US) \\ Darryl Symonds, RD Instruments \\ Ning Xiao, LinkQuest Inc. \\ Tim Cook, Flotation Technologies, Inc. \\ Charles Abbott, Evans-Hamilton, Inc.
}

\begin{abstract}
A problem for the offshore oil and gas industry is obtaining complete real-time current profiles in water depths greater than $1200 \mathrm{~m}$, the present maximum range of a single RD Instruments Acoustic Doppler Current Profiler (ADCP) meter. Increasing commercial activity in those depths and the desire to further understand deep ocean processes drives this need. A solution that implements a two-meter system utilizing underwater acoustic modems was developed. The study tested a dual-meter system that integrated surface and bottom mounted ADCP systems. The challenges addressed were uncertain performance of the modems and the ADCPs due to the noisy underwater acoustic environment and a potential lack of deep water acoustic backscattering. The significant advantage of a real-time data acquisition system is providing operational guidance for the rig activities and the ability to control the system in effort to optimize profiling range and performance.
\end{abstract}

\section{INTRODUCTION}

Shell Oil Company and other offshore commercial operators typically collect oceanographic data and meteorological data from their platforms. There are many reasons for ocean current data acquisition by the oil and gas industry. Some are:

- Measurements help improve our understanding of ocean processes and further process model development.

- Ocean current criteria for structural design are based on rare events. These events are better represented in databases comprising extensive measurements.

- Operational needs for real-time current information include: platform installation, rig orientation, riser and tubular deployment/recovery, remotely operated vehicle (ROV) operation, estimation of potential component fatigue, identification of ocean current process, and work boat station-keeping.

Measuring current profiles from offshore rigs using ADCPs helps satisfy many of these needs.

Recent analysis of observations of significant deep ocean currents, as observed in $2000 \mathrm{~m}$ waters near the Sigsbee Escarpment in the Gulf of Mexico by Texas A\&M University, has increased industry concern over presence of previously unknown, strong deep flows [1]. It has been suggested that bottom intensified barotropic topographic Rossby waves are the source of these relatively unknown processes [2].
Presently, the maximum profiling range is about $1200 \mathrm{~m}$ with a single RD Instruments (RDI) Ocean Surveyor meter. Shell is presently operating and exploring in water depths greater than this range. To increase the vertical profiling coverage, Shell Global Solutions (US) has worked with RDI, LinkQuest, Inc., Evans-Hamilton, Inc., and Flotation Technologies, Inc. in developing a multi-meter real-time current measurement system. The system employs LinkQuest, Inc. underwater acoustic modems to transmit the data from a bottom mounted ADCP to the surface in real time. Deploying an upward looking bottom mounted meter has the advantage of optimizing the acoustic signal by applying the greatest power in the region of lowest backscattering.

A prototype system was successfully tested last year in $900 \mathrm{~m}$ water depth using a $300 \mathrm{kHz}$ RDI Workhorse (WH) Sentinel. The result was $100 \%$ accurate data transmission. A deployment at a $1574 \mathrm{~m}$ water depth drilling site with a bottom mounted RDI $75 \mathrm{kHz}$ WH Long Ranger in mid-July 2001 explored not only the data transmission reliability, but also the back-scattering environment in the deep ocean.

\section{PRIOR STUDIES}

Recent deep data taken in the Gulf of Mexico with $75 \mathrm{kHz}$ ADCPs indicate that there may be a dearth of effective backscattering at depths greater than $1500 \mathrm{~m}$ for low frequency acoustic Doppler measurements. Deployments of downward-looking low frequency ADCP meters mounted at mid-column in deep water have achieved extremely diminished profiling range.

Since deep water currents are of great interest to scientists around the world, a technique was developed to acquire deep current profiles. Starting in 1988, ADCPs were mounted onto CTD rosette packages and were used to collect profile data as the system is lowered through the water column. The profile data collected while the rosette is lowered is combined and a single full ocean profile is constructed.

RDI has worked with these scientists to analyze the collected data. The data analyzed has shown a very repeatable trend in the backscatter concentration in the water at depths. Water depths greater than $1500 \mathrm{~m}$ show a significant drop in the concentration of backscatter at depths between 900-1100m, (from customer reviewed data at RDI, 1998-2000). The data analyzed also show that when the water depth is greater than $2000 \mathrm{~m}$, the backscatter below 
$1100 \mathrm{~m}$ can be so small as to reduce the profiling range of a system by up to $60 \%$ for ADCPs at a $300 \mathrm{kHz}$ frequency. ADCPs at $150 \mathrm{kHz}$ have lost as much as $80 \%$ of their profiling range at depths below $1100 \mathrm{~m}$ due to the reduced backscatter.

Tests performed in the Gulf of Mexico with a Broad Band (BB) $75 \mathrm{kHz}$ ADCP (a system capable of collecting $400-500 \mathrm{~m}$ of range in depths above $1000 \mathrm{~m}$ ) mounted at $1500 \mathrm{~m}$ of depth in $3000 \mathrm{~m}$ of water were unable to obtain more than $40 \mathrm{~m}$ of range [3]. The data showed that the backscatter was so low that little to no reflected energy was received by the ADCP.

Dr. Tim Boyd of Oregon State University conducted a study with a WH Long Ranger $75 \mathrm{kHz}$ off of the coast of Oregon in $2700 \mathrm{~m}$ of water. His results showed that when the meter was deployed in approximately $1400 \mathrm{~m}$ water depth, different maximum profiling ranges were possible, depending on if the system was mounted upward or downward facing. When upward facing ranges of up to $600 \mathrm{~m}$ were possible. When the deployment was changed to downward facing, ranges were reduced to $400 \mathrm{~m}$ [4].

Another test by Dr. Boyd used the same WH Long Ranger $75 \mathrm{kHz}$ deployed upward looking off of the coast of Hawaii. In $1447 \mathrm{~m}$ of water, the profiling ranges varied from $600 \mathrm{~m}$ at night to less than $300 \mathrm{~m}$ in the day. Associated with this change were large changes in the returned signal strength in the profile. This change is presumed to be caused from the migration of plankton even at these depths.

It was thought that using the WH Long Ranger $75 \mathrm{kHz}$ at a depth of nearly $1600 \mathrm{~m}$ presented the possibility that the range of the system may be reduced so that quality data would not be obtained. However, by mounting the ADCP upward facing (thus pointing into the area of the strongest backscatter), and the ability of manipulating the ADCP configuration in real-time using the underwater acoustic modems, a reasonable amount of range could be obtained.

\section{INSTRUMENTATION}

Shell Oil Company is performing drilling operations from the Transocean Sedco Forex Deepwater Nautilus platform in the Gulf of Mexico in $1574 \mathrm{~m}$ of water. The platform is equipped with an RDI BB VM75kHz ADCP. This BB ADCP is mounted in the port pontoon of the platform and is sitting approximately 9 meters below the surface. This system is providing real time data for the top 500 meters of water.

An upward looking RDI WH Long Ranger $75 \mathrm{kHz}$ ADCP was mounted at the bottom of the sea floor to measure the lower portion of the water column. The Long Ranger ADCP is a totally self-contained meter and is part of the RDI WorkHorse ADCP product family, using RDI's Broad Band transmission and processing. The Long Ranger ADCP was chosen because it provides the longest profiling range from any self-contained instrument in the world.
To facilitate the ability to communicate and change the setup of the WH Long Ranger, a set of LinkQuest acoustic modems were used. LinkQuest Inc. manufactures high-speed underwater acoustic modems that combine recent advances in high-speed digital communication, such as Digital Subscriber Line and cellular communication, with broadband underwater acoustics. Tailored for various ocean environments, these modems achieve a high data rate, robustness and low power consumption. A bit error rate of less than $10^{-7}$ has been consistently observed in the field [5].

At the end of 1999, LinkQuest Inc. worked with Shell Global Solutions (US) and Evans-Hamilton, Inc. to deploy a set of their UWM2000 modems in the Gulf of Mexico in high-noise offshore drilling environment. From 3 November to 19 December 1999, LinkQuest's UWM2000 acoustic modem was deployed with a $300 \mathrm{kHz}$ RDI Workhorse ADCP at $900 \mathrm{~m}$ below sea surface from an actively drilling platform. While data were transmitted through the acoustic link in realtime at 9600 baud, the ADCP recorder was also used. By comparing the logged current ensembles at the surface PC, obtained through the acoustic link, and the current ensembles in the ADCP recorder, it is concluded that there was no loss of any current ensemble and no error in the data [5]. The success of the deployment prompted Shell to adopt LinkQuest's deepwater UWM4000 modems for this $1600 \mathrm{~m}$ test on the Deepwater Nautilus. The UWM4000 modem reaches $4000 \mathrm{~m}$ in range and rates up to $4800 \mathrm{bits} / \mathrm{second}$ in standard mode and 9600 bits/second in optional mode. The modem operates at a frequency band centered on $17 \mathrm{kHz}$.

Floatation Technologies, Inc. developed a sub-surface deployment buoy that held the RDI WH Long Ranger ADCP and the LinkQuest UWM4000 acoustic modem. Flotation Technologies' Flotec-3000 low-density syntactic foam provides the buoyancy component of the buoy package. This material is designed for years of continuous service at $3000 \mathrm{~m}$ depth. The remaining materials are constructed from either Type 316 stainless steel or titanium for minimum corrosion over extended deployments and all dissimilar metals are isolated to prevent galvanic corrosion.

This buoy was designed to house an RDI WH Long Ranger ADCP in either the upward or downward facing direction and to house a LinkQuest acoustic modem and external battery pack. The buoy measuring 40 inches in diameter has a positive buoyancy of approximately $200 \mathrm{lbs}$. with the RD WH Long Ranger and LinkQuest Modem and External Battery cases loaded. Based on this positive buoyancy and the currents expected in the area, Flotation Technologies recommended a $600 \mathrm{lb}$ anchoring weight. This is 3 times the positive buoyancy of the assembly, and was selected to keep the assembly from "walking" during potential high current activity. Due to the proximity of this system to the oil-drilling site, the mooring was configured as ROV deployable/recoverable, but was designed to also incorporate acoustic release technology. 
The system was designed with enough positive buoyancy to minimize mooring inclination, and assure an adequate assent rate.

On 23 July 2001, a WH Long Ranger 75kHz ADCP, the LinkQuest acoustic modem, and the Flotation Technologies buoy were moored from the Deepwater Nautilus through the on-board ROV owned and operated by Oceaneering. The ROV placed the mooring at a depth of $1574 \mathrm{~m}$ on the bottom of the Gulf of Mexico. Once in place the ADCP was approximately $6 \mathrm{~m}$ off of the ocean bottom.

\section{DATA}

Real-time data was collected for a period of 3 hours, from 0200-0500 on 25 July 2001, from the WH Long Ranger $75 \mathrm{kHz}$ ADCP. Each instrument was setup with $16 \mathrm{~m}$ bins, the narrowest $\mathrm{BB}$ mode, and 20 minute ensemble intervals. To conserve batteries, the WH Long Ranger was setup to average 48 pings spaced every 25 seconds in each 20 minute ensemble. The BB VM was powered directly from the platform and so could be setup to collect 800 pings, spaced every 1.5 seconds in each 20 minute ensemble.

With this setup, a total of 10 ensembles were collected with each of the instruments. The data was processed to determine the profiling range of the ADCP. The correlation data were used to determine the end of the range. Correlation data represent how well the returned signals correlate to themselves. A correlation peak of 1 would be perfect correlation and 0 would be completely uncorrelated data. The correlation data is scaled inside the ADCP to a unit less value of 0-255 counts, representing correlation values from $0-1$.

Correlation data is normalized inside the ADCP, such that the expected correlation value output will be 127 counts (representing the expected correlation of 0.5). Correlation values are screened by the ADCP at each depth cell and on each ping. A depth cell containing a value below 64 counts will cause the velocity on that beam, at that depth cell, to be rejected by the ADCP. Rejected velocity data is not used in the East, North, and Vertical velocity calculations for that ping and will not appear in the average velocity for the ensemble. Although a velocity data point is rejected, the correlation for that particular cell will be averaged in the ensemble data. This allows the user to be able to perform a secondary threshold check using correlation data. To determine the end of range in the data collected, the correlation values for all four beams were averaged together in each of the ensembles. The first depth cell to have an average correlation value of less than 64 counts became the end of the range for that profile.

Table 1 represents the expected and actual ranges obtained (using the correlation cutoff threshold) for each of the systems used.

TABLE 1

Predicted Range of RDI's WH Long Ranger $75 \mathrm{kHz}$ and BB VM 75kHz ADCPs

\begin{tabular}{|l|l|l|l|}
\hline $\begin{array}{l}\text { Depth } \\
\text { Cell } \\
\text { Size }\end{array}$ & Operational Setup & $\begin{array}{l}\text { Expected } \\
\text { Range (m) }\end{array}$ & $\begin{array}{l}\text { Actual } \\
\text { Range (m) }\end{array}$ \\
\hline $16 \mathrm{~m}$ & $\begin{array}{l}\text { WH Long Ranger } \\
\text { Narrowest BB Mode }\end{array}$ & $614^{*}$ & 969 \\
\hline $16 \mathrm{~m}$ & $\begin{array}{l}\text { BB VM 75kHz } \\
\text { Narrowest BB Mode }\end{array}$ & $627^{* *}$ & 633 \\
\hline
\end{tabular}

Calculated with RDI SC Deployment Software for a temperature of $4^{\circ} \mathrm{C}$ and a salinity of $35 \mathrm{ppt}$.

** Calculated with RDI BBSETUP Deployment Software for a temperature of $4{ }^{\circ} \mathrm{C}$ and a salinity of $35 \mathrm{ppt}$.

The above data indicates the ranges from the WH Long Ranger are much greater than expected. According to an RDI White Paper [6], when looking up through the water column it is possible that the range may be extended because of the increase in the backscatter. To determine if there was indeed an increase in the backscatter concentration at the end of the profiling range, the Echo Intensity data from the WH Long Ranger was reviewed.

All WH and BB ADCPs collect Echo Intensity data through a circuit that measures the return signal strength (RSSI). RSSI data is relative to the instrument, and therefore will indicate the strength of the signal as the ADCP receives it. This means that the first depth cell will always be seen as a stronger signal then the second depth cell and the third depth cell. This trend will continue to end of the profiling range when in open ocean, and no other strong reflector is contacted such as the surface or the bottom. This effect is caused by both spreading and absorption losses in the water. It is possible to convert the RSSI data from being relative to the ADCP into a $\mathrm{dB}$ value that represents the relative backscatter concentration in the water. This is done by removing the spreading loss, absorption loss, and scaling the data to $\mathrm{dB}$. Appendix A contains the conversion formula.

To obtain a single view of the backscatter concentration, first the RSSI data for the 4 individual beams is averaged into a single average RSSI profile for each ensemble. Then the 3 ensembles in the center of the WH Long Ranger data (which represents 1 hour of time) are set to compare the relative signal strength. 

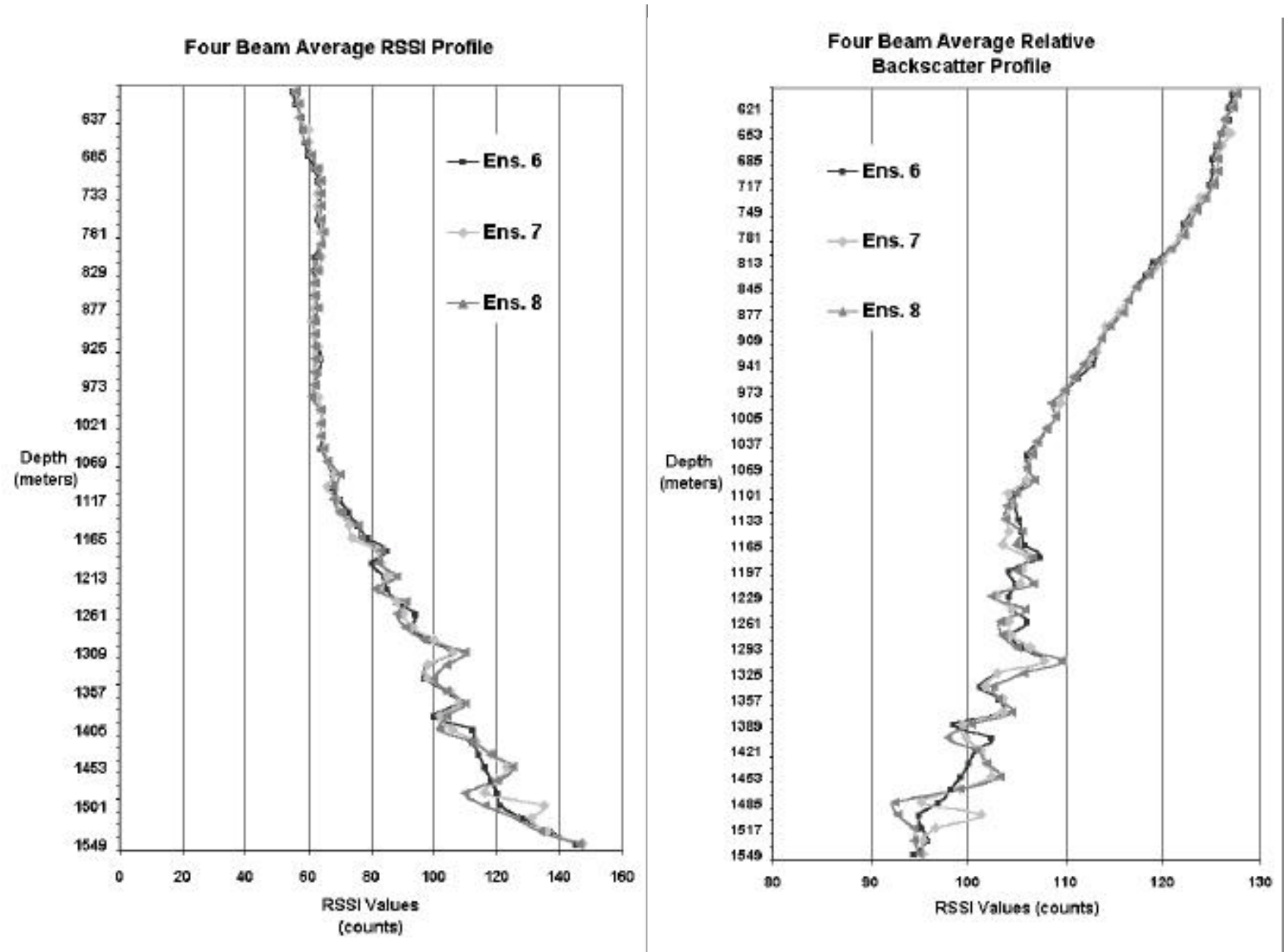

Fig.1. Four Beam Average RSSI and Relative Backscatter Profiles

Figure 1 displays two profile plots. The left profile plot shows the WH Long Ranger RSSI values (in counts), from ensembles 6-8, versus depth. The right profile plot shows the same data, but it has been converted into relative backscatter in $\mathrm{dB}$. In these plots, it can be seen that all 3 of the average RSSI profiles are on top of each other. This suggests that not just a single ensemble measurement obtained this return signal strength. The Relative Backscatter profile indicates that as the range away from the WH Long Ranger increases, the backscatter strength increases. This means that as the WH Long Ranger signal is moving toward the surface, the concentration of suspended particles is increasing. This increase in backscatter allows the WH Long Ranger to profile farther because the increase in returned signal strength is stronger than the "normally" expected losses due to absorption and spreading. This indicates that, at this water depth in this particular area of the Gulf of Mexico, there are enough suspended particles to allow the expected profiling performance of the WH Long Ranger ADCP.

Using the data from the WH Long Ranger and the data from the BB VM $75 \mathrm{kHz}$ system, it was possible to create a profile of the entire water column. The data from these 2 systems overlapped for about $50 \mathrm{~m}$ at the end of each of their ranges. The data overlap provided for confirmation that both systems were reading the same velocity, and that the method used to determine the end of the range for the WH Long Ranger system was reasonable.

Velocity data from the BB VM $75 \mathrm{kHz}$ ADCP had been collected for several weeks at this location in the Gulf of Mexico, so the upper part of the profile was well known. Based on Oceaneering ROV measurements, the velocity in the bottom half of the profile was expected to be approximately $25 \mathrm{~cm} / \mathrm{sec}$ from $600-1000 \mathrm{~m}$, falling off to less than $10 \mathrm{~cm} / \mathrm{sec}$ for ranges of $1000-1500 \mathrm{~m}$.

Figure 2 presents a $1500 \mathrm{~m}$ profile of magnitude and direction. This profile was created with the data from both the RDI BBVM and the RDI WH Long Ranger ADCPs. All 10 ensembles from each system were averaged into a single profile representing a 3-hour average. This figure shows very good agreement with the overlapped data from the two instruments, and agreed well with the expected velocities in the profile. This information gave confidence that the extended range of the WH Long Ranger allowed for the collection of accurate water currents. 

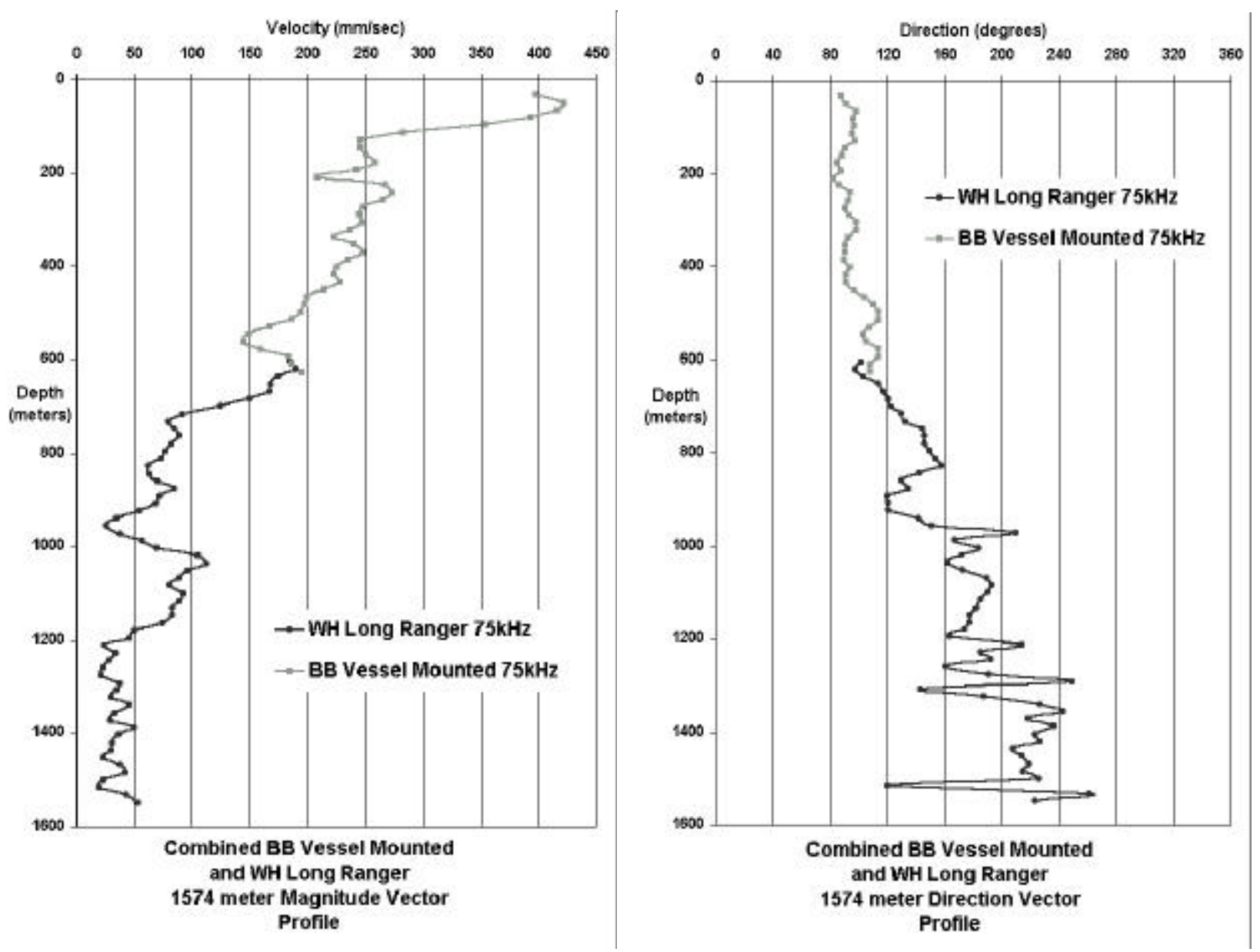

Fig. 2. $1500 \mathrm{~m}$ Profile with BB VM $75 \mathrm{kHz}$ and a WH Long Ranger $75 \mathrm{kHz}$

During this experiment, a number of short interval ensembles with a variety of depth cell sizes and operational bandwidths modes were collected. When the data was analyzed, it was discovered that the LinkQuest acoustic modems operating at $17 \mathrm{kHz}$, produce harmonics that were received by the RDI WH Long Ranger $75 \mathrm{kHz}$ ADCP. These harmonics interfered with the WH Long Ranger returned signals, and the data was contaminated.

However, this experiment showed that this real time configuration is possible, and that to avoid this interference issue, the setup of the WH Long Ranger must be done so that it is not actively pinging while the acoustic modems are transferring data. This is easily accomplished given that when in actual use, the WH Long Ranger would be setup for 10-20 minute ensemble intervals. This provides more than enough overhead time to prevent interference.

\section{CONCLUSION}

Through observations of many data sets, from many regions, typically the concentration of suspended materials decreases with an increase in water depth. Typically, the concentration of suspended material drops off rapidly below
$900-1100 \mathrm{~m}$. However, the deeper the water is the larger the drop off is at this depth. As an example, water that is $5000 \mathrm{~m}$ deep will have a lower concentration of suspended materials at $900-1100 \mathrm{~m}$, than what is found in water that is only $2000 \mathrm{~m}$ deep.

We have found at this site, in a water depth of $1600 \mathrm{~m}$, that there are enough suspended materials to allow for normal operation of an ADCP. Suspended materials did not limit profiling range, and the real time data collection package using a bottom mounted RDI WH Long Ranger ADCP with LinkQuest UWM4000 Acoustic Modems in a Flotation Technologies Buoy, is a viable way to complete a $1600 \mathrm{~m}$ profile.

The authors realize that this is but one case and that many experiments in both the Gulf of Mexico and other measurements are required before any definitive conclusions can be drawn concerning current profiling range and suspended material concentration. In deep water, regional, spatial, and temporal variations will affect ranges obtained. More experiments are anticipated in the Gulf of Mexico as the requirement for deeper water profiles continues. 


\section{Acknowledgements}

The author and co-authors of this paper would like to thank Herb Mayo, Bill Burt and Ian Hammill, a few of the many people at Shell Oil Company who enabled this study to happen. Transocean Sedco Forex personnel including Mike Williams, Steve Manasco, Tom Brahin, the Transocean crane personnel, and Howard Day (Oceaneering ROV superintendent) and his crew were critical in getting all of the equipment on board the Deepwater Nautilus, making it available to work with, and helping with the deployment of the buoy. Without their team effort, this deployment would not have been possible. We would also like to thank Dan Cote of Flotation Technologies for his work in designing the buoy, running the initial form, and performing fit tests. His work allowed us to complete the package for this study.

A special thank you goes out to all of the ADCP users who have shared their data and experiences with RDI so that we would have the experience to know some of what to expect when we were attempting this test.

\section{APPENDIX A}

Equation 1.1 for RSSI to Relative Backscatter Conversion Formula:

$\mathrm{DB}=\left(\mathrm{RSSI}_{\mathrm{dB}} * \mathrm{RSSI}\right)+\left(20 * \mathrm{LOG}(\mathrm{R})+\left(2 *\left(\mathrm{~A}_{\mathrm{C}}\right) *(\mathrm{R})\right)(1.1)\right.$

Where:

$\operatorname{RSSI}_{\mathrm{dB}}=$ RSSI counts to $\mathrm{dB}$ conversion

$\operatorname{RSSI}_{\mathrm{dB}}=0.45$ for WH Long Ranger

RSSI $=$ RSSI raw value (counts)

$\mathrm{R}=$ Range in meters to the depth cell

$\mathrm{A}_{\mathrm{C}}=$ Absorption Coefficient

$A_{C}=0.022$ for this installation

\section{REFERENCES}

[1] S.F. DiMarco, R.O. Reid, A.E. Jochens, W.D. Nowlin, Jr., and M.K. Howard, "General Characteristics of Currents in the Deepwater Gulf of Mexico," OTC 12993, May 2001.

[2] P. Hamilton, "Deep currents in the Gulf of Mexico," J. Phys. Oceanogr., vol. 20, pp. 1087-1104, 1990.

[3] R. Hamilton (Evans-Hamilton, Inc.), Houston, TX, personal communication, 2000.

[4] P. Devine, D. Symonds (RD Instruments) San Diego, CA, personnel conversation with Tim Boyd at Oregon State University (2001) and review of test data collected off the coast of Oregon and Hawaii.

[5] X. Yu, "Wireline Quality Underwater Wireless Communication Using High Speed Acoustic Modems", Oceans 2000, Rhode Island, 2000.

[6] J. Gast, (RD Instruments) San Diego, CA, "Deep Profiling, A White Paper for Shell Oil", 2000. 